\title{
Intergroup relationships and quality improvement in healthcare
}

Jean M Bartunek

Correspondence to Dr Jean M Bartunek, Department of Organization Studies, Boston College, 140 Commonwealth Avenue, Chestnut Hill, MA 02467-3808, USA; bartunek@bc.edu

Accepted 25 September 2010

\begin{abstract}
Background: Intergroup problems among physicians, nurses and administrators in healthcare settings sometimes retard such settings' ability to foster enhanced quality of care. Without knowledge of the social dynamics that generate the difficulties, it is impossible to address some crucial issues that may affect quality initiatives.

Methods: This paper reviews three types of dynamics, social identity, communities of practice and socialisation into particular professional identities that affect relationships among professional groups in healthcare settings.

Recommendations: A suggestion is made for the creation of cross-boundary communities of practice, socialisation into them and dual, superordinate identities as a means to foster more effective intergroup dynamics and, thus, contribute to a greater quality of care.
\end{abstract}

Those who carry out quality improvement initiatives in healthcare must focus on enhancing systems, structures, measurements and adaptive action. ${ }^{1-3}$ Also necessary are positive working relationships among groups such as physicians, nurses and healthcare administrators whose collaboration is required for quality improvement initiatives to succeed. ${ }^{1}{ }^{4-7}$ There are obviously many more groups in addition to physicians, nurses and administrators whose collaboration is necessary for successful healthcare delivery. These include, among others, dieticians, multiple types of therapists, pharmacists, laboratory technicians and so forth. However, the preponderance of studies has focused on these three groups. Their intergroup relationships may serve as proxies for others. The purpose of this paper is to address crucial issues regarding such relationships and suggest means of fostering them in the service of enhanced quality.

Relationships among physicians, nurses and healthcare administrators may be positive; they may respect each other, share similar goals and work together to accomplish joint aims. ${ }^{8}$ Often, however, relationships among the groups are not so positive. For example, physicians do not always trust healthcare administrators to understand them or appreciate their legitimate needs. ${ }^{9}$ Physicians are more likely than nurses to think that the two groups are working well together, ${ }^{10}{ }^{11}$ perhaps because physicians' higher status makes them less aware of difficulties that nurses experience in the relationship. ${ }^{6}{ }^{12} \mathrm{Cohn}^{13}$ noted that "physician-relations issues provoke not only practical but also desperate ideas from healthcare executives.'

Rifts among these groups have negative impacts on quality. ${ }^{1}$ Patient care in ICUs suffers when there are differences in nurses' and physicians' knowledge bases. ${ }^{14}$ Nurses are sometimes afraid of reporting errors because of concerns about administrators' responses, ${ }^{15}$ and when they encounter problems they may solve them but may not communicate the solutions to others who should know about them. ${ }^{16}$ Medical staff at a US hospital complained that the CEO and her administrative team interfered with initiatives and recommendations essential to improving quality. ${ }^{17}$ Ferlie and Shortell ${ }^{18}$ discussed a cultural divide between clinical and managerial cultures in healthcare that is a 'deterrent to quality improvement work.'

Disagreements among physicians, nurses and administrators are frequently discussed as communication problems. ${ }^{1} 1920$ However, communication difficulties are often symptomatic of subtle but pervasive intergroup dynamics problems. It is crucial to determine how to diagnose these deeper issues and to work with them to foster more effective intergroup relationships in healthcare. The intergroup dynamics I will discuss are social identity, ${ }^{21}$ communities of practice ${ }^{22}$ and socialisation into professional identities. ${ }^{23}$ 


\section{INTERGROUP DYNAMICS IN HEALTHCARE}

\section{Social identity}

Tajfel and Turner's ${ }^{21}{ }^{24}$ social identity theory focused on how people's self-esteem derives at least partly from the social groups with which they identify. Identification with valued groups brings benefits, including personal security, companionship, bonding and greater well-being after life-threatening events such as strokes. ${ }^{25}{ }^{26}$ Further, identification with a professional group facilitates behaviour consistent with that identity. For example, in one study, the more nurses identified with the nursing profession, the more likely they were to get vaccinated. ${ }^{27}$

People often accomplish a positive social identity by comparing their own group favourably to others, something that happens almost instinctively. ${ }^{28}$ For example, members of a particular political party will probably see other political parties as deficient to theirs. Further, they often assume that their own group is complex and diverse, while members of other groups are relatively similar and homogeneous. ${ }^{21} 2429$ These perceptions further their self-esteem ${ }^{24}$ and help accomplish the other benefits of social identity. Thus, social identity theory suggests that it is very normal for physicians, nurses and hospital administrators to see their own group as much more complex than other groups and to value its contributions particularly highly.

\section{Communities of practice}

Communities of practice are 'groups of interdependent participants [that] provide the work context within which members construct shared identities and the context that helps those identities to be shared. Members of such groups collectively develop an outlook on work. ${ }^{30}$ Consistent with social identity theory, members of a community of practice view activity within it as significantly more complex and valuable than do outsiders. ${ }^{31}$

Communities of practice develop tacit forms of knowledge that can be learnt only through participation in the community. Such learning occurs in several ways, including metaphors, stories of practice and masterapprentice socialisation. ${ }^{32}$ In such learning, ${ }^{33}$ apprentices learn their roles in the community by participating in its activities along with more expert members and eventually inculcating community norms. ${ }^{34}$

For example, the placements nurses receive after their formal training, and thus the different communities of practice they experience, have important impacts on what they learn about how nursing is really carried out. ${ }^{35}$ Separate communities of practice also contribute to differences in knowledge bases between physicians and nurses in ICU units. $^{14}$

Knowledge 'leaks' within communities of practice, since members continually share information. ${ }^{30}$ But knowledge does not easily leak between communities of practice. ${ }^{14}$ For instance, research-based scientific evidence sometimes has a weak relationship with clinical behaviour change in health services, in part because this knowledge has to flow across the boundaries between scientists and clinicians. ${ }^{36}$ The lack of means of sharing tacit knowledge between communities of practice was a primary reason for the problems experienced by breakthrough collaboratives in accomplishing their quality improvement aims in the National Health Service. ${ }^{37}$

\section{Socialisation into a professional identity}

The development of professional identities within the communities of practice of physicians, nurses or healthcare administrators is complex, involving finegrained processes over time, as newcomers gain tacit knowledge of what their roles really mean in their community. ${ }^{38}$ Bosk ${ }^{39}$ for example, described the use of horror stories as moral parables, the severe consequences of normative as opposed to technical errors, and the absolute power of attending physicians as crucial to how new surgeons learn over time to view themselves as free to make their own decisions and practice as they alone decide. Mizrahi ${ }^{40}$ showed how contending norms of efficiency and compulsiveness in a southern US hospital shaped the socialisation of internal medicine residents and led them to think of their purpose as getting rid of patients.

Pratt, Rockman and Kauffmann ${ }^{23}$ studied how professional identification formed among medical residents in primary care, surgery and radiology. The model they developed is complex, but, focusing solely on the radiologists, it can be summarised as follows. During their first year of residency, radiology residents' work consisted primarily of sitting through teaching conferences, assigned readings and formal exams. Shortly into their first year, the residents felt useless and started to label themselves as (still) medical students rather than physicians. However, once they started becoming involved in 'baby calls' in which they assisted more senior residents during some evenings and weekends, they slowly started to flesh out for themselves their identities as radiologists. Eventually, they came to identify themselves primarily as consultants to other physicians, rather than as doctors who healed people.

Thus, when, after their residencies, physicians arrive to work at a healthcare setting, they do not come with blank slates. Rather, they arrive with well-inculcated professional identities that have been forged over years and whose focus is the physician role. Their identities carry with them tacit knowledge and shared social identities that only those who have experienced similar training can understand. 
Nurses ${ }^{41} 42$ and healthcare administrators ${ }^{43}$ are also socialised into the communities of practice associated with their professional roles. So, it is not surprising that when the different groups interact, there is often difficulty in working well across communities.

\section{Impacts of social identity, communities of practice and socialisation}

Social identities aligned with the communities of practice into which healthcare professionals have been socialised contribute to intractable identity conflicts ${ }^{17}$ that may have severe consequences for implementing quality initiatives. For example, boundaries between groups of healthcare professionals retarded the spread of potentially valuable innovations such as managing anticoagulation service provision with a computer support system and laparoscopic surgery for inguinal hernia repair in the UK National Health System. ${ }^{44}$ This negative outcome was attributed in part to the fact that 'important knowledge boundaries as well as social or identity boundaries inhibited diffusion. The evidence or knowledge underpinning the innovations did not flow readily across the professions: rather, it "stuck" within them.' Ferlie et al suggested the professional socialisation of healthcare personnel as a cause of difficulties in sharing across boundaries: 'The professional communities stimulate learning and change internally but block such processes externally, given the social boundaries between neighbouring professions. ${ }^{44}$

\section{IMPROVING INTERGROUP RELATIONSHIPS IN HEALTHCARE SETTINGS}

What can be done to foster improved intergroup relationships in healthcare in the service of improved quality? It is clear that communication across communities of practice needs improvement, ${ }^{2}$ though as noted above, communication difficulties are often more a symptom than an underlying problem. There is, however, some cause for optimism; in Ferlie et al's ${ }^{44}$ study 'The construction of a genuine multidisciplinary community of practice was rare, but possible.' In this section of the paper, I will suggest some ways in which communities of practice, socialisation and social identity may help achieve more positive intergroup relations.

\section{Communities of practice}

Efforts have been undertaken to foster more effective collaboration across healthcare communities of practice. For example, Bate, Mendel and Robert ${ }^{4}$ note that for quality improvement goals to be met in healthcare settings it is crucial that there be cross-organisational and cross-occupational communities of practice that share knowledge about the quality agenda.
One means of fostering cross-disciplinary communities of practice in healthcare is cross-discipline Crew Resource Management (CRM) training, ${ }^{45-48}$ which is adapted from the aviation industry. The intent of such training is to improve outcomes of patient care by enhancing communication between healthcare professionals ${ }^{47}$ in part by addressing underlying problems such as status issues. Thus, for example, CRM includes training for lower-ranking groups such as nurses in raising concerns and for higher-ranking groups such as physicians in hearing them. ${ }^{49}$ By these means, hopefully boundaries between communities of practice can be made more permeable. ${ }^{750}$ More information about CRM training can be found at http://www.saferhealthcare. com/cat-shc/crew-resource-management.

Participants value CRM training, ${ }^{48}{ }^{51}$ at least when it takes place in relatively short learning segments. Yet there is no clear evidence of its long-term impacts. Further, the roles and impacts of social identities and socialisation are not an explicit focus of CRM training. But these affect how successfully CRM or equivalent initiatives address underlying issues associated with communication.

\section{Socialisation}

As noted above, with some exceptions, ${ }^{52}$ socialisation processes for physicians, nurses and healthcare administrators lead them to identify strongly with their profession rather than their workplace. ${ }^{23} 53$ But it is possible for socialisation processes to foster more effective intergroup relationships as well. This can occur if there are active efforts to have socialisation carried out by cross-disciplinary communities of practice. ${ }^{52}{ }^{53}$ Such socialisation might take place, for example, when medical students are on rotation if those charged with their learning form interdisciplinary communities of practice that model positive relationships. ${ }^{52}$

\section{Social identities}

For successful cross-boundary work, it is necessary to expand participants' social identities beyond their professions. One promising step is to help participants add second identities focused on the healthcare setting itself. These may be superordinate identities that encompass multiple groups. ${ }^{17} 54 \quad 55$ When group members succeed in accomplishing superordinate, shared identities, intergroup bias among them tends to be reduced. ${ }^{56}$

There are several means that might help people accomplish this dual identification. Leaders can take some initiatives, and individual members can take others.

\section{Leader initiatives}

Leaders can foster dual identities by facilitating the creation of superordinate goals that encompass the 
concerns of both the individual professions and the health setting. ${ }^{17} 57$ This might happen, for example, by setting joint goals for the workplace that foster comparison with other workplaces.

In addition, several strategies can be taken to foster sharing across boundaries. Richter et a ${ }^{58}$ suggest that healthcare administrators communicate 'organisational successes, values, and goals' to all groups of healthcare professionals. They can also promote into boundary spanning positions physicians, nurses and administrators who feel strong ties with both their profession and their organisation. Finally, Richter et al also suggest the value of intergroup meetings and social gatherings.

Leaders can also facilitate dual identities by taking steps to help increase members' comfort in working with other groups. For example, they may help members of all professional groups to consider conflict between them as potentially positive, as ways of bringing new information to the surface rather than simply a sign of intergroup problems. ${ }^{8}$ They may also attempt to contribute to feelings of psychological safety in intergroup relationships, ${ }^{6}$ by being open, inclusive and nonjudgemental about the experiences of members of all professional groups. This can help members of the various teams be more open to trying new types of relationships, even if they encounter difficulties at first.

\section{Interpersonal relationships}

Cross-boundary friendships have a strong impact on group members' ability to develop more expansive identities. Tropp ${ }^{59}$ suggests that close cross-group friendship is crucial for successful intergroup relationships; such friendships 'compel us to be more generous in interpreting outgroup members' intentions and behaviours, such that we begin to grant them the same kinds of positive associations that we typically reserve for members of our own groups.' Further, it is not necessary for members of particular groups to experience such friendships themselves. The knowledge that other members of one's own group have friends in other groups also fosters positive intergroup relationships and expanded identities. ${ }^{60}$

The importance of creating structural conditions that foster intergroup relationships and the importance of friendship are not typically dealt with by those focusing only on communication problems. However, they are crucial for more effective intergroup identification to endure in healthcare settings.

\section{Value of dual identities for quality}

The successful creation of dual, superordinate identities can help foster quality care. Richter et $a l,{ }^{58}$ for example, studied intergroup relationships across groups of healthcare providers (eg, nursing teams, general practices, health visiting teams) in five primary care trusts in the UK. They found that if members of these groups identified with the primary care trusts in which they were working as well as their own professional group, dual identification shifted the members' focus to common, shared superordinate goals without blurring their professional group boundaries. The common goals helped to enhance the setting's productivity, at least if there was frequent contact across groups.

\section{CONCLUSION}

I have suggested some underlying dynamics that may interfere with groups of healthcare professionals working together. I have also suggested some means of responding to the dynamics, especially fostering crossgroup communities of practice, socialisation consistent with this, and dual professional-setting identities. The creation of dual identities within healthcare settings is not easy to accomplish. However, it may be particularly important as a means of fostering intergroup collaboration in the service of quality.

Acknowledgements I am very grateful to F Davidoff, P Batalden, L Leviton and $C$ Vincent for their extremely helpful comments on earlier drafts of this paper.

Competing interests None.

Provenance and peer review Not commissioned; externally peer reviewed.

\section{REFERENCES}

1. Batalden PB, Davidoff F. What is 'quality improvement' and how can it transform healthcare? Qual Saf Health Care 2007;16:2-3.

2. Hudelson P, Cleopas A, Kolly V, et al. What is quality and how is it achieved? Practitioners' views versus quality models. Qual Saf Health Care 2008;17:31-6.

3. Rangachari P. Knowledge sharing networks related to hospital quality measurement and reporting. Health Care Manage Rev 2008;33:253-63.

4. Bate P, Mendel P, Robert G. Organizing for Quality: The Improvement Journeys of Leading Hospitals in Europe and the United States. Oxford: Radcliffe Publishing, 2008.

5. Tucker AL, Nembhard IM, Edmondson AC. Implementing new practices: an empirical study of organizational learning in hospital intensive care units. Manage Sci 2007;53:894-907.

6. Nembhard IM, Edmondson AC. Making it safe: the effects of leader inclusiveness and professional status on psychological safety and improvement efforts in health care teams. J Organ Behav 2006;27:941-66.

7. Mørk BE, Aanestad M, Hanseth O, et al. Conflicting epistemic cultures and obstacles for learning across communities of practice. Knowl Process Manage 2008;15:12-23.

8. Dovidio JF, Saguy T, Shnabel N. Cooperation and conflict within groups: bridging intragroup and intergroup processes. J Soc Issues 2009;65:429-49.

9. Ramirez IL, Bartunek JM. The multiple realities of organization development consultation in health care. J Organ Change Manage 1989;2:40-57.

10. Thomas EJ, Sexton JB, Helmreich RL. Discrepant attitudes about teamwork among critical care nurses and physicians. Crit Care Med 2003;31:956-9.

11. O'Leary KJ, Ritter CD, Wheeler H, et al. Teamwork on inpatient medical units: assessing attitudes and barriers. Qual Saf Health Care 2010;19:117-21.

12. Sirota T. Nurse/physician relationships: improving or not? Iss Nurs 2007;37:53-5.

13. Cohn $\mathrm{KH}$. Changing physician behavior through involvement and collaboration. J Healthc Manag 2009;54:80-6. 
14. Stein-Parbury J, Liaschenko J. Understanding collaboration between nurses and physicians as knowledge at work. Am J Crit Care 2007:16:470-7; quiz 8.

15. Elder NC, Brungs SM, Nagy M, et al. Intensive care unit nurses' perceptions of safety after a highly specific safety intervention. Qual Saf Health Care 2008;17:25-30.

16. Tucker AL, Edmondson AC. Why hospitals don't learn from failures: organizational and psychological dynamics that inhibit system change. Calif Manage Rev 2003;45:55-72.

17. Fiol CM, Pratt MG, O'Connor EJ. Managing intractable identity conflicts. Acad Manage Rev 2009;34:32-55.

18. Ferlie EB, Shortell SM. Improving the quality of health care in the United Kingdom and the United States: a framework for change. Milbank Q 2001;79:281-315.

19. Leonard M, Graham S, Bonacum D. The human factor: the critical importance of effective teamwork and communication in providing safe care. Qual Saf Health Care 2004:(13 Suppl 1):i85-90.

20. Manser T, Howard SK, Gaba DM. Adaptive coordination in cardiac anaesthesia: a study of situational changes in coordination patterns using a new observation system. Ergonomics 2008;51:1153-78.

21. Tajfel H. Social-psychology of inter-group relations. Ann Rev Psychol 1982;33:1-39.

22. Brown JS, Duguid P. Organizational learning and communities-ofpractice: toward a unified view of working, learning, and innovating. Organ Sci 1991;2:40-58.

23. Pratt MG, Rockmann KW, Kaufmann JB. Constructing professional identity: the role of work and identity learning cycles in the customization of identity among medical residents. Acad Manage $J$ 2006; 49:235-62.

24. Tajfel $\mathrm{H}$, Turner JC. An integrative theory of intergroup conflict. In: Austin WG, Worchel S, eds. The Social Psychology of Intergroup Relations. Monterey, CA: Brooks Cole, 1979:33-47.

25. Haslam SA, Jetten J, Postmes T, et al. Social identity, health and well-being: an emerging agenda for applied psychology. Appl Psychol: An Int Rev 2009;58:1-23.

26. Haslam C, Holme A, Haslam SA, et al. Maintaining group memberships: social identity continuity predicts well-being after stroke. Neuropsychol Rehabil 2008;18:671-91.

27. Falomir-Pichastor J, Toscani L, Despointes SH. Determinants of flu vaccination among nurses: the effects of group identification and professional responsibility. Appl Psychol Int Rev 2009;58:42-58.

28. Hogg MA, Terry DJ. Social identity and self-categorization processes in organizational contexts. Acad Manage Rev 2000;25:121-40.

29. Tajfel H, ed. Differentiation Between Social Groups: Studies in the Social Psychology of Intergroup Relations. London: Academic Press, 1978.

30. Brown JS, Duguid P. Knowledge and organization: a social-practice perspective. Organ Sci 2001;12:198-213.

31. Kuhn T. Negotiating boundaries between scholars and practitioners: knowledge, networks, and communities of practice. Manage Commun Q 2002;16:106-12.

32. Bartunek J, Trullen J, Bonet E, et al. Sharing and expanding academic and practitioner knowledge in health care. J Health Serv Res Policy 2003;(8 Suppl 2):62-8.

33. Lave I, Wenger E. Situated Learning: Legitimate Peripheral Participation. New York: Cambridge University Press, 1991

34. Gherardi S, Nicolini D. Learning the trade: a culture of safety in practice. Organization 2002:9:191-223.

35. Cope $\mathrm{P}$, Cuthbertson $\mathrm{P}$, Stoddart $\mathrm{B}$. Situated learning in the practice placement. J Adv Nurs 2000;31:850-6.

36. Ferlie E, Fitzgerald L, Wood M. Getting evidence into clinical practice: an organisational behaviour perspective. J Health Serv Res Policy 2000;5:96-102.

37. Bate SP, Robert G. Knowledge management and communities of practice in the private sector: lessons for modernizing the national health service in England and Wales. Public Admin 2002;80:643-63.

38. Lingard L, Reznick R, DeVito I, et al. Forming professional identities on the health care team: Discursive constructions of the 'other' in the operating room. Med Educ 2002;36:728-34.
39. Bosk C. Forgive and Remember. Chicago: University of Chicago Press, 1979

40. Mizrahi T. Getting Rid of Patients: Contradictions in the Socialization of Physicians. Piscataway, NJ: Rutgers University Press, 1986.

41. Reutter L, Field PA, Campbell IE, et al. Socialization into nursing: nursing students as learners. J Nurs Educ 1997;36:149-55.

42. Roberts D. Learning in clinical practice: the importance of peers. Nurs Stand 2008;23:35-41.

43. Denis JL, Langley A, Pineault M. Becoming a leader in a complex organization. J Manage Stud 2000;37:1063-99.

44. Ferlie E, Fitzgerald L, Wood M, et al. The nonspread of innovations: the mediating role of professionals. Acad Manage $J$ 2005;48:117-34.

45. Wilson KA, Burke CS, Priest HA, et al. Promoting health care safety through training high reliability teams. Qual Saf Health Care 2005; 14:303-9.

46. Musson DM, Helmreich RL. Team training and resource management in health care: Current issues and future directions. Harv Health Policy Rev 2004;5:25-35.

47. Dunn EJ, Mills PD, Neily J, et al. Medical team training: applying crew resource management in the Veterans Health Administration. $J t$ Comm J Qual Patient Saf 2007;33:317-25.

48. Grogan EL, Stiles RA, France DJ, et al. The impact of aviation-based teamwork training on the attitudes of health-care professionals. $J \mathrm{Am}$ Coll Surg 2004;199:843-8

49. Elder NC, Brungs SM, Nagy M, et al. Nurses' perceptions of error communication and reporting in the intensive care unit. $J$ Patient Safety 2008;4:162-8.

50. Handley K, Sturdy A, Fincham R, et al. Within and beyond communities of practice: making sense of learning through participation, identity and practice. J Manage Stud 2006;43:641-53.

51. Haller G, Garnerin P, Philippe MA, et al. Effect of crew resource management training in a multidisciplinary obstetrical setting. Int $J$ Qual Health Care 2008:20:254-63.

52. Jaye C, Egan T, Smith-Han K. Communities of clinical practice and normalising technologies of self: learning to fit in on a surgical ward. Anthropol Med 2010;17:59-73.

53. McNair RP. The case for educating health care students in professionalism as the core content of interprofessional education. Med Educ 2005;39:456-64.

54. Gaertner SL, Dovidio JF, Banker BS, et al. Reducing intergroup conflict: From superordinate goals to decategorization, recategorization, and mutual differentiation. Group Dyn Theory Res Pract 2000;4:98-114.

55. Dovidio JF, Gaertner SL, Saguy T, et al. From when to why: Understanding how contact reduces bias. In: Wagner U, Tropp LR, Finchilescu G, et al, eds. Improving Intergroup Relations: Building on the Legacy of Thomas F Pettigrew. Malden, MA: Wiley-Blackwell, 2008:75-90.

56. Brewer MB. Deprovincialization: social identity complexity and outgroup acceptance. In: Wagner U, Tropp LR, Finchilescu G, et al, eds. Improving Intergroup Relations: Building on the Legacy of Thomas F Pettigrew. Malden, MA: Wiley-Blackwell, 2008:160-76.

57. Stone $\mathrm{CH}$, Crisp RJ. Superordinate and subgroup identification as predictors of intergroup evaluation in common ingroup contexts. Group Process Intergroup Relat 2007:10:493-513.

58. Richter AW, West MA, Van Dick R, et al. Boundary spanners' identification, intergroup contact, and effective intergroup relations. Acad Manage J 2006;49:1252-69.

59. Tropp LR. The role of trust in intergroup contact: its significance and implications for improving relations between groups. In: Wagner U, Tropp LR, Finchilescu G, et al, eds. Improving Intergroup Relations: Building on the Legacy of Thomas F Pettigrew. Malden, MA: WileyBlackwell, 2008:91-106.

60. Vonofakou C, Hewstone M, Voci A, et al. The impact of direct and extended cross-group friendships on improving intergroup relations. In: Wagner U, Tropp LR, Finchilescu G, et al, eds. Improving Intergroup Relations: Building on the Legacy of Thomas F Pettigrew. Malden, MA: Wiley-Blackwell, 2008:107-23. 